\title{
Cumulative radiation dose exposure in three consecutive fluoroscopy - Guided lumbar spine epidural steroid injections
}

\author{
I. Evansa',2, A. Hadunkina ${ }^{1,2}$, V. Dzabijeva ${ }^{2}$, N. Zlobina ${ }^{2}$, N. Ivanovs ${ }^{2}$, I. Vanags ${ }^{1}$, O. \\ Sabelnikovs ${ }^{1}$. \\ ${ }^{1}$ Riga Stradins University, Anaesthesiology, Intensive Care Department, Riga, Latvia. \\ ${ }^{2}$ Riga 1st Hospital, Anaesthesiology, Intensive Care and Pain Clinics, Riga, Latvia.
}
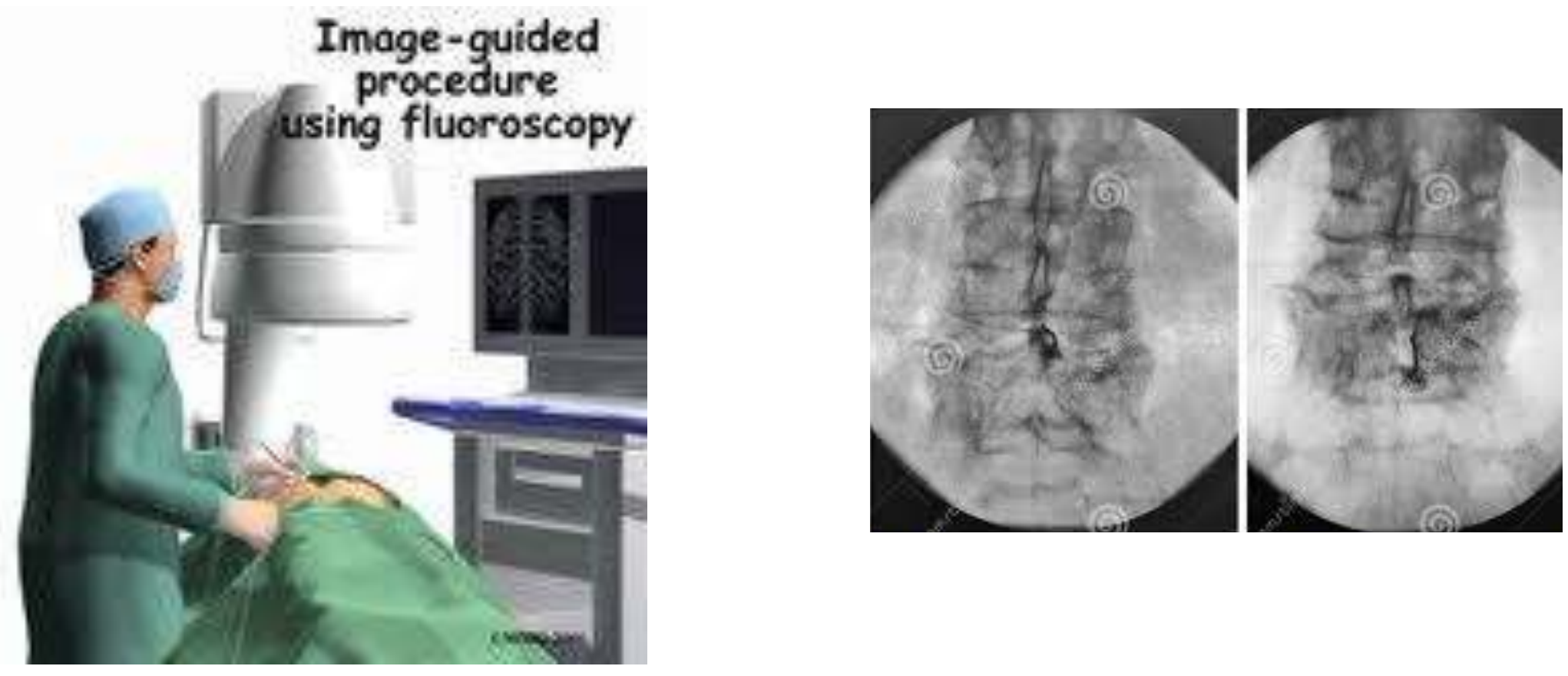

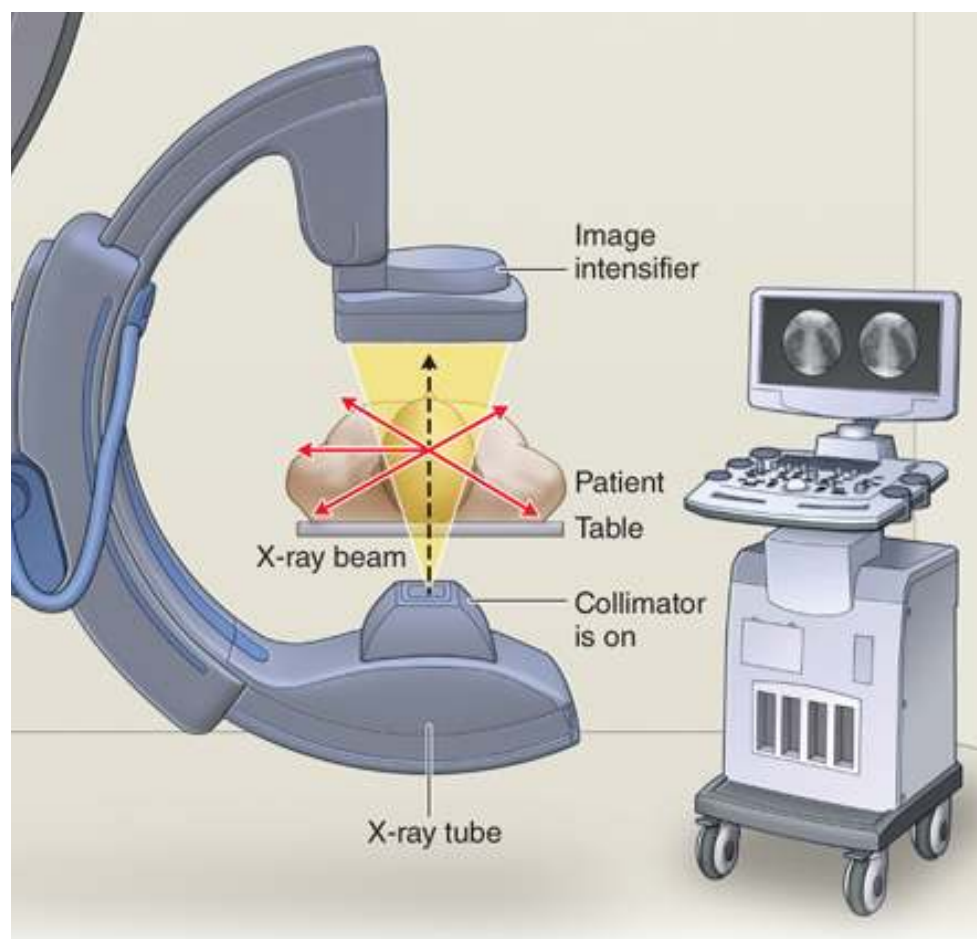

Background and Aims:

Fluoroscopy-guided epidural steroid injections (ESI) are widely used for managing low back pain (LBP). ESI has associated risks stemming from patient and radiologist radiation exposure. Monitoring radiation dose is mandatory to minimize risks. Radiation doses to patients during ESI have been reported, but there is lack of date on cumulative radiation dose in patients receiving more than one ESI. No universally accepted reference level is available for fluoroscopy-guided spinal pain management. This study was undertaken to determine radiation exposure during median and paramedian approach at L4-L5 level in patients, who receive course of three consecutive ESI. As well as to find factors that may correlate with higher radiation dose or longer fluoroscopy time (FT)

\section{Methods:}

Fluoroscopy-guided ESI was performed in 56 patients. Fluoroscopy time (FT) and dose area product (DAP) were recorded for all patients; correlations between FT and DAP were determined in three consecutive ESI procedures. Patients were categorized into three groups low back pain (LBP) duration for two years, five years, and more than five years. Independent-t test was used to compare FT in patients younger then 60 and older than 60 years.

All procedures were performed by one experienced pain specialist and one radiologist using single-plane fluoroscopy machine (Symens).

FT and DAP were recorded automatically by the fluoroscopy equipment.

Results:

1. 48 females and 8 men, mean age 56 years (from 47 till 94 years) with LBP anamnesis for mean 4.6 years (min 3 month; max 20 years) underwent three consecutive ESI.

2. Cumulative DAP for three ESI procedures was mean 872.57 cGycm2 (SD 275.53) and mean FT 70.39 (SD 17,69) seconds (s); strong positive correlation between FT and DAP $(r=0.755$; $p=0.01)$ is revealed.

3. $\quad$ FT (mean) were during $1^{\text {st }}$ procedure $24.5 \mathrm{~s}$, during $2^{\text {nd }} 23.6 \mathrm{~s}$ and $22.3 \mathrm{~s}$ during $3^{\text {rd }}(\min$ time $8 \mathrm{~s}$; $\max 52 \mathrm{~s})$.
4. The mean DAP were during $1^{\text {st }}$ procedure $294,67 \mathrm{cGycm}^{2}$, during $2^{\text {nd }} 287,79 \mathrm{cGycm}^{2}$ and during $3^{\text {rd }} 296,61 \mathrm{cGycm}^{2}$ (min DAP 100,23; maximal 753,48 $\mathrm{cGycm}^{2}$ ).

5. FT and DAP were positively correlated in each group, respectively at $1^{\text {st }}$ ESI time $\rho 0,750(p=0.01) ; 2^{\text {nd }} 0,797(p=0.01) ; 3^{\text {rd }} 0,682$ $(p=0.01)$.

6. Significantly $(\mathrm{p}=0.05)$ longer first FT was in patients, who suffered from LBP symptoms for more than 5 year $n=13$ (mean $1^{\text {st }}$ FT 29.38s); in comparison with those, who had anamnesis for LBP less 1 year $n=13$ (mean $1^{\text {st }}$ FT 21s) and 1 till 5 years $\mathrm{n}=30$ (mean $1^{\text {st }}$ FT $21.27 \mathrm{~s}$ ). Significant difference $(p=0.05)$ in mean DAP between mentioned groups is revealed for all three procedures, DAP was higher during all three procedures in those, who suffered from LBP longer than 5 years.

\section{Conclusions:}

DAP is widely used and reported as a benchmark measure to measure total X-ray energy and to estimate stochastic injury. FT is measured easily, providing a way to monitor the amount of radiation used. In our study FT is in strong uphill linear relationship with DAP. The Society of Interventional Radiology-Cardiovascular and Interventional Radiological Society of Europe (SIR-CIRSE) defined the significant radiation dose threshold using a DAP of $500 \mathrm{~Gy} \cdot \mathrm{cm}^{2}$ and FT of 40-60 minutes.

In the present study, the mean cumulative DAP was $8.73 \mathrm{~Gy} \cdot \mathrm{cm}^{2}$, which is 57 times lower and mean FT 1 minute 10s. Also, we conclude that patients with longer anamnesis for LBP have longer FT and higher DAP, which is probably due to more severe degenerative spinal lesions. 